\title{
Male partner antenatal clinic attendance is associated with increased uptake of maternal health services and infant BCG immunization: a national survey in Kenya
}

Beryne Odeny ${ }^{1 *} \mathbb{D}$, Christine J. McGrath ${ }^{1}$, Agnes Langat ${ }^{5}$, Jillian Pintye ${ }^{1,2}$, Benson Singa ${ }^{6}$, John Kinuthia ${ }^{7}$, Abraham Katana ${ }^{5}$, Lucy Ng'ang'a ${ }^{5}$ and Grace John-Stewart ${ }^{1,3,4}$

\begin{abstract}
Background: Male partner antenatal clinic (ANC) attendance may improve maternal uptake of maternal child health $(\mathrm{MCH})$ services.

Methods: We conducted a cross-sectional survey of mother-infant pairs attending week-6 or month-9 infant immunizations at 120 high-volume MCH clinics throughout Kenya. Clinics were selected using probability proportionate to size sampling. Women were interviewed using structured questionnaires and clinical data was verified using $\mathrm{MCH}$ booklets. Among married women, survey-weighted logistic regression models accounting for clinic-level clustering were used to compare outcomes by male ANC attendance and to identify its correlates.

Results: Among 2521 women attending MCH clinics and had information on male partner ANC attendance, 2141 (90\%) were married of whom 806 (35\%) had male partners that attended ANC. Among married women, male partner ANC attendance was more frequent among women with higher education, women who requested their partners to attend ANC, had male partners with higher education, did not report partner violence, and had disclosed their HIV status ( $p<0.001$ for each). Additionally, male ANC attendance was associated with higher uptake of ANC visits [adjusted Odds Ratio (AOR) $=1.67,95 \%$ confidence interval $(C l) 1.36-2.05$, ], skilled delivery ( $A O R=2.00$, 95\% Cl 1.51-2.64), exclusive breastfeeding ( $A O R=1.70,95 \% \mathrm{Cl} 1.00-2.91$ ), infant Bacille Calmette Guerin (BCG) immunization ( $\mathrm{AOR}=3.59,95 \% \mathrm{Cl} 1.00-12 \cdot 88)$, and among HIV-infected women, antiretroviral drugs $(\mathrm{aOR}=6.16$, 95\% Cl 1.26-30.41).
\end{abstract}

Conclusion: Involving male partners in $\mathrm{MCH}$ activities amplifies benefits of $\mathrm{MCH}$ services by engaging partner support for maternal uptake of services.

Keywords: Maternal child health, Antenatal care, Male partner, Attendance, Involvement, HIV

\section{Background}

Maternal and child health $(\mathrm{MCH})$ services are widely available in sub-Saharan Africa, however, maternal and infant mortality and morbidity remain unacceptably high $[1,2]$. Access to $\mathrm{MCH}$ services is a first step to receiving antenatal care (ANC), postnatal care (PNC), family

\footnotetext{
* Correspondence: bodeny@uw.edu

'Department of Global Health, University of Washington, 325 9th Ave \#359909, Seattle, WA, USA

Full list of author information is available at the end of the article
}

planning, infant immunizations, growth monitoring, and prevention of mother-to-child transmission of HIV (PMTCT) interventions and is key to healthy maternal and infant outcomes [3]. World Health Organization (WHO) guidelines recommend that pregnant women attend at least 4 ANC visits as part of focused antenatal care (FANC) [1]. However, uptake of FANC and other $\mathrm{MCH}$ services among Kenyan women is low $(<90 \%)$ [2-4].

In Kenya, as in other low resource settings, socioeconomic and cultural factors limit women's autonomy to access maternal and infant health services $[2,5,6]$. 
Women remain vulnerable to gender inequality norms and economic constraints that increase their dependence on men and undermine their independent access to $\mathrm{MCH}$ services $[5,6]$. As a result, decision-making that affects women's and children's health often rests on male partners [7]. Understanding the role played by men and the need to involve male partners in $\mathrm{MCH}$ services has become more widely recognized [7, 8]. Male ANC attendance has been recognized as a strategy for male involvement in $\mathrm{MCH}$ [9-11]. Enabling men to visit ANC provides an opportunity to educate men on maternal and child health while fostering their favorable attitudes toward access of services [12, 13]. There is some evidence to suggest that male ANC attendance may enhance access to skilled deliveries, antenatal care, and use of antiretroviral drugs (ARVs) for PMTCT [6, 10, 11, 14-18]. Unfortunately, male partner ANC attendance is often low and efforts to encourage it may be suboptimal $[15,19,20]$.

As part of a national survey, we evaluated the prevalence and correlates of male ANC attendance and its association with maternal uptake of antenatal and PMTCT services among married, postpartum women.

\section{Methods}

\section{Study design and sampling framework}

We conducted a cross-sectional facility-based survey in $\mathrm{MCH}$ clinics throughout Kenya between June and December 2013 to assess coverage and uptake of antenatal and PMTCT services. MCH clinics that provided routine $\mathrm{MCH}$, including PMTCT services, were included in the sampling frame. Facilities in Wajir, Mandera and Garissa counties and facilities with $<500$ ANC visits in 2011, as reported to the National AIDS and STI Control Programme (NASCOP), were excluded from the sampling frame due to logistical constraints. This sub-analysis includes data from the primary PMTCT-MCH survey which used probability proportionate to size sampling to randomly select 120 of 540 facilities with $\geq 500$ ANC visits per year in 44 of 47 counties in Kenya (Fig. 1).

\section{Participant eligibility and study procedures}

Trained study teams, consisting of one nurse and one laboratory technician, collected data from eligible participants during a 5-day window per clinic. Women were eligible if they were the biological mothers bringing their infants for routine week 6 or month 9 infant immunizations and were willing and able to provide written informed consent.

Staff-administered structured questionnaires were used to gather information on male ANC attendance and maternal and partner sociodemographic characteristics as reported by the mother. Partner characteristics included age, level of education, employment status, HIV

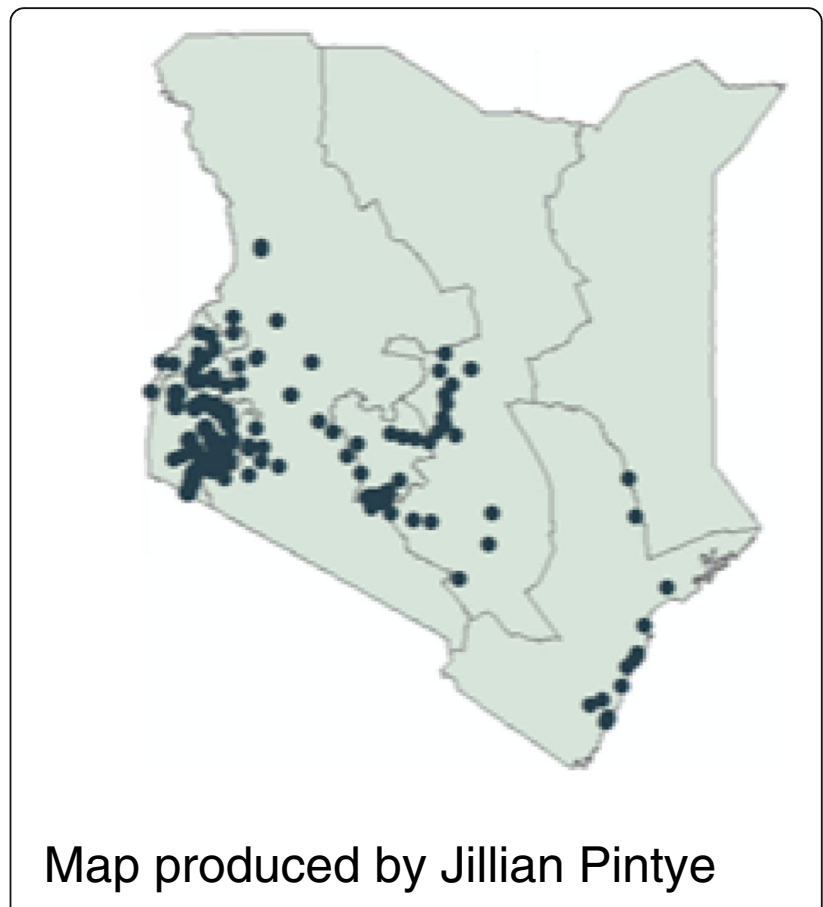

Fig. 1 Sites surveyed across Kenya. Map produced by Jillian Pintye

status, and provision of financial support. Maternal sociodemographic characteristics included age, marital status, relationship duration, education level, employment status, partner support, maternal orphan status, and intimate partner violence (IPV). IPV was assessed using the four-items: Hurt, Insulted, Threatened with Harm, and Screamed (HiTS) Domestic violence screening tool, measuring the frequency a partner hurts, insults, threatens or screams [21]. A 'yes' to any of the four items was defined as presence of IPV. Sharing a toilet with another household was used as a proxy measure of socioeconomic status. Clinical information included maternal and infant HIV status, gestational age at first ANC visit, number of ANC visits, and uptake of ARVs for PMTCT. MCH booklets were used to confirm maternal ANC attendance, skilled delivery, ARVs for PMTCT, and infant BCG immunization.

All participants provided written informed consent prior to enrollment in the study. Ethical approvals were obtained from the University of Washington Human Subjects Division, the Kenya Medical Research Institute, and the Associate Director for Science at the U.S. Centers for Disease Control and Prevention (CDC).

\section{Statistical analysis}

Analyses were restricted to married women who had male partner ANC attendance data to control for unmeasured effects of relationship type and stability on male ANC attendance. A woman was considered to be married, if she reported that she was in a monogamous 
or polygamous marriage or was in a "come-we-stay" relationship with her male partner. Only married women with information on male partner ANC attendance were analyzed. We conducted analyses to estimate prevalence and correlates of male ANC attendance, and determine associations between male ANC attendance and maternal and infant health outcomes among married women. Chi-square tests were used to compare characteristics of the mother and her male partner by male ANC attendance. Logistic regression with odds ratios (OR), adjusted ORs (AOR), and 95\% confidence intervals (CI) were used to analyze covariates. Continuous data were analyzed and presented using medians and interquartile ranges. Male ANC attendance was also compared by maternal HIV status. All estimates were weighted to reflect probability for selection of each study clinic and adjusted for clustering at the clinic level. Age and education were modeled as continuous and ordinal variables, respectively. Maternal age and education were included in multivariable logistic regression a priori assumptions based on their known associations with uptake of maternal health services. All analyses were conducted using Stata 13.0 svy commands (STATA Corporation, College Station, Texas).

\section{Results}

\section{Study population}

Of 2521 mother-infant pairs enrolled, analyses were done on 2141 women $(90 \%)$ who were married and had partner attendance data. Their median age was 25 years (Interquartile range (IQR) 22-30 years) and adolescent mothers aged $10-19$ years, accounted for $10 \%(n=173)$ of married women (Table 1). Forty four percent $(n=974)$ of married women had attained at least secondary level education and $36 \%(n=808)$ were employed. Forty-one percent $(n=894)$ of married women experienced some form of IPV. Sixty three percent $(n=1346)$ of married women reported they had at least one living parent and $58 \%(n=1279)$ reported

Table 1 Maternal correlates for male partner ANC attendance among married women ${ }^{a}$

\begin{tabular}{|c|c|c|c|c|c|c|c|}
\hline & \multicolumn{3}{|c|}{ Unweighted N (Weighted \%) or Weighted Median (IQR) } & \multirow[b]{3}{*}{ OR $(95 \% \mathrm{Cl})$} & \multirow[b]{3}{*}{$P$-value } & \multirow[b]{3}{*}{$\operatorname{AOR}(95 \% \mathrm{Cl})^{\mathrm{b}}$} & \multirow[b]{3}{*}{$P$-value } \\
\hline & \multicolumn{3}{|c|}{ Partner attended ANC } & & & & \\
\hline & $\operatorname{Total}^{\complement}(n=2141)$ & No $(n=1335)$ & Yes $(n=806)$ & & & & \\
\hline HIV positive & $158(7)$ & $106(7)$ & $52(7)$ & $1.05(0.69-1.59)$ & 0.811 & $1.21(0.66-2 \cdot 24)$ & 0.537 \\
\hline Median age, years & $25(22-30)$ & $25(21-30)$ & $24(22-29)$ & $0.98(0.96-0.99)$ & 0.046 & $0.97(0.95-0.99)$ & 0.006 \\
\hline \multicolumn{8}{|l|}{ Requested partner to attend ANC } \\
\hline No & $774(41)$ & $711(58)$ & $63(9)$ & Reference & & Reference & \\
\hline Yes & $1366(59)$ & $623(42)$ & $743(91)$ & $14 \cdot 16(10.09-19 \cdot 87)$ & $<0.001$ & $13.31(9 \cdot 21-19 \cdot 21)$ & $<0.001$ \\
\hline \multicolumn{8}{|l|}{ Maternal education } \\
\hline$\leq$ Primary & $1167(56)$ & $830(67)$ & $337(45)$ & Reference & & Reference & \\
\hline Secondary & $678(31)$ & $382(25)$ & $296(37)$ & $2.26(1.77-2 \cdot 87)$ & $<0.001$ & $2.26(1.77-2.88)$ & $<0.001$ \\
\hline$>$ Secondary & $296(13)$ & $123(8)$ & $173(18)$ & $3.5(2.58-4.94)$ & $<0.001$ & $3.82(2 \cdot 75-5 \cdot 31)$ & $<0.001$ \\
\hline \multicolumn{8}{|l|}{ Employed } \\
\hline No & $1311(64)$ & $849(66)$ & $462(60)$ & Reference & & Reference & \\
\hline Yes & $808(36)$ & $468(34)$ & $340(40)$ & $1.33(1.07-1.66)$ & 0.012 & $1.21(0.94-1.56)$ & $0 \cdot 152$ \\
\hline Disclosed HIV status to partner & $2036(96)$ & $1245(93)$ & 791 (98) & $3.28(1.60-6.75)$ & 0.001 & $3.07(1.41-6.67)$ & 0.005 \\
\hline Among HIV positive & $135(86)$ & $88(81)$ & $47(90)$ & $1.82(0.53-6.27)$ & 0.342 & $1.84(0.66-5.08)$ & $0 \cdot 241$ \\
\hline Among HIV negative & $1900(97)$ & $1156(94)$ & 744 (99) & $4.07(1.61-10.33)$ & 0.003 & $3.64(1.46-9.04)$ & 0.006 \\
\hline Has other male partners & $78(3)$ & $49(3)$ & $29(3)$ & $1.08(0.63-1.84)$ & 0.776 & $1.03(0.57-1.88)$ & 0.916 \\
\hline \multicolumn{8}{|l|}{ Intimate partner violence } \\
\hline No & $1247(59)$ & $717(52)$ & $530(67)$ & Reference & & Reference & \\
\hline Yes & $894(41)$ & $618(48)$ & $276(33)$ & $0.55(0.44-0.68)$ & $<0.001$ & $0.61(0.46-0.79)$ & $<0.001$ \\
\hline Not orphaned & $1346(63)$ & $831(63)$ & $515(63)$ & $1.02(0.82-1.27)$ & 0.871 & $0.87(0.69-1 \cdot 10)$ & 0.140 \\
\hline \multicolumn{8}{|l|}{ Shared toilet } \\
\hline No & $862(42)$ & $507(40)$ & $355(44)$ & Reference & & Reference & \\
\hline Yes & $1279(58)$ & $828(60)$ & $451(56)$ & $0.72(0.58-0.89)$ & 0.003 & $0.73(0.57-0.95)$ & 0.017 \\
\hline
\end{tabular}

${ }^{a}$ All estimates account for sampling design and clinic-level clustering

${ }^{\mathrm{b}}$ Multivariable model adjusting for maternal age and maternal education

${ }^{c}$ Married women without partner attendance data were excluded from the analysis 
sharing a toilet with another household. Among married women, 7\% $(n=153)$ were HIV-positive.

Median age of married male partners was 30 years (IQR 26-35 years) (Table 2). Sixty percent of men had attained at least secondary school education $(n=1257)$, $87 \%$ had some form of employment $(n=2142)$, and 98\% $(n=2165)$ provided financial support to their spouses. Among $77 \%(n=1509)$ of women who reported knowing their spouses' HIV status, $4 \%(n=76)$ of male partners were HIV-positive.

\section{Prevalence and correlates of partner attendance}

Thirty five percent of male partners attended ANC (Table 2). Older women were less likely to have their male partners attend ANC. The likelihood of male ANC attendance lowered with each increasing year of maternal age $[\mathrm{AOR}=0.97(0.95-0.99), P=0.006]$. Male partner ANC attendance was less likely if there was a history of IPV $[\mathrm{AOR}=0.61(0.46-0.79), p<0.001]$ and if women reported their households shared a toilet $[\mathrm{AOR}=0.73$ (0.57-0.95), $p=0.017$ ] (Table 1). Conversely, male ANC attendance was associated with maternal disclosure of HIV status [AOR = 3.07 (1.41-6.67), $\mathrm{p}=0.005$ ]. Women who completed at least secondary school were more than two times as likely to have their male partners attend ANC compared to those with primary or no education $[\mathrm{AOR}=2.26(1.77-2.88), p<0.001]$. Male partner attendance was 13 times higher among men asked to attend clinic by their spouses than those not asked not to attend $[\mathrm{AOR}=13.31(9.21-19 \cdot 21), \mathrm{p}<0.001]$. Women with secondary education $[\mathrm{AOR}=1.77(1.42-2.22), p<0.001]$ and higher than secondary education $[\mathrm{AOR}=2.97(2.14-$ $4.11), p<0.001]$ were twice as likely to request their partners to come to ANC compared to women with primary or no education (Table 3). Positive maternal HIV status was also associated with a significantly higher likelihood of women requesting their partners to attend ANC $[\mathrm{AOR}=$ 1.79 (1.11-2.90), $p=0.017$ ] (Table 3).

Male partners were more likely to attend ANC if they completed secondary school $[\mathrm{AOR}=1.42(1.06-1.90)$, $p=0.018]$ or college [AOR $=1.90(1.24-2.85), p=0.003$ ] as compared to men with less education. Older men were less likely to attend ANC than younger men $[\mathrm{AOR}=0.97$ per increasing year of age (0.96-0.99), $p=0.002]$, and male partners with multiple children were less likely to attend ANC than male partners with fewer children $[A O R=0.76$ (0.66-0.88), $p<0.001]$. Additionally, male partners in longer duration relationships were less likely to accompany their spouses to ANC compared to those in more recent relationships $[\mathrm{AOR}=0.92$ per increasing year $(0.89-0.95)$, $p<0.001$ ] (Table 2). Male partner employment, provision of financial support, and HIV status were not associated with ANC attendance.

\section{Maternal uptake of MCH and PMTCT services and male ANC attendance}

After adjusting for maternal age and education and clustering at the clinic level, women whose male partners

Table 2 Paternal Correlates of Male ANC attendance ${ }^{a}$

\begin{tabular}{|c|c|c|c|c|c|c|c|}
\hline & \multicolumn{3}{|c|}{ Unweighted N (Weighted \%) or Weighted Median (IQR) } & \multirow[b]{3}{*}{ OR $(95 \% \mathrm{Cl})$} & \multirow[b]{3}{*}{$p$-value } & \multirow[b]{3}{*}{$\operatorname{AOR}(95 \% \mathrm{Cl})^{\mathrm{b}}$} & \multirow[b]{3}{*}{$p$-value } \\
\hline & \multicolumn{3}{|c|}{ Partner attended ANC (35\%) } & & & & \\
\hline & $\overline{\operatorname{Total}^{c}(n=2141)}$ & No $(n=1335)$ & Yes $(n=806)$ & & & & \\
\hline Median age, years & $30(26-35)$ & $30(26-37)$ & $30(27-35)$ & $0.97(0.96-0.99)$ & $<0.001$ & $0.97(0.96-0.99)$ & 0.002 \\
\hline \multicolumn{8}{|l|}{ Age, categorized } \\
\hline $18-25$ years & $209(11)$ & $135(12)$ & $74(10)$ & Reference & & Reference & \\
\hline $25-35$ years & $1090(54)$ & $607(45)$ & $483(62)$ & $1.57(1.08-2.30)$ & 0.019 & $1.40(0.96-2.06)$ & 0.082 \\
\hline$>35$ years & $696(35)$ & $501(43)$ & $195(28)$ & $0.76(0.51-1 \cdot 14)$ & $0 \cdot 186$ & $0.84(0.53-1.34)$ & 0.466 \\
\hline \multicolumn{8}{|l|}{ Education } \\
\hline$\leq$ Primary & $786(40)$ & $564(49)$ & $222(31)$ & Reference & & Reference & \\
\hline Secondary & $873(43)$ & $535(40)$ & $338(45)$ & $1.78(1.38-2.29)$ & $<0.001$ & $1.42(1.06-1.90)$ & 0.018 \\
\hline$>$ Secondary & $384(17)$ & $164(11)$ & $220(24)$ & $3 \cdot 24(2 \cdot 38-4 \cdot 40)$ & $<0.001$ & $1.90(1.24-2 \cdot 85)$ & 0.003 \\
\hline Employed & $2142(87)$ & $1162(85)$ & $713(88)$ & $1.26(0.89-1.78)$ & 0.193 & $1.11(0.79-1.55)$ & 0.558 \\
\hline Provides financial support & $2165(98)$ & $1297(97)$ & $794(99)$ & $2.37(0.77-7 \cdot 26)$ & 0.132 & $2.28(0.64-8.14)$ & 0.206 \\
\hline Partner tested for HIV & $1509(77)$ & $812(69)$ & $682(91)$ & $4.32(3.12-5.99)$ & $<0.001$ & $3.67(2.63-5.13)$ & $<0.001$ \\
\hline HIV positive & $76(4)$ & $47(4)$ & $29(4)$ & $0.98(0.57-1.70)$ & 0.948 & $1.20(0.70-2.07)$ & 0.514 \\
\hline Median relationship duration, years & $4(2-8)$ & $5(2-10)$ & $3(1 \cdot 5-6)$ & $0.92(0.90-0.95)$ & $<0.001$ & $0.92(0.89-0.95)$ & $<0.001$ \\
\hline Median number of children & $3(2-4)$ & $3(2-4)$ & $2(2-3)$ & $0.75(0.67-0.83)$ & $<0.001$ & $0.76(0.66-0.88)$ & $<0.001$ \\
\hline
\end{tabular}

${ }^{a}$ All estimates account for sampling design and clinic-level clustering

${ }^{\mathrm{b}}$ Multivariable model adjusting for maternal age and maternal education

${ }^{c}$ Married women without partner attendance data were excluded from the analysis 
Table 3 Characteristics of married women who requested their partners to attend $\mathrm{ANC}^{\mathrm{a}}$

\begin{tabular}{|c|c|c|c|c|c|c|c|}
\hline & \multicolumn{3}{|c|}{ Unweighted N (Weighted \%) or Weighted Median (IQR) } & \multirow[b]{3}{*}{ OR $(95 \% \mathrm{Cl})$} & \multirow[b]{3}{*}{$P$-value } & \multirow[b]{3}{*}{$\operatorname{AOR}(95 \% \mathrm{Cl})^{\mathrm{b}}$} & \multirow[b]{3}{*}{$P$-value } \\
\hline & \multicolumn{3}{|c|}{ Requested Partner to attend ANC } & & & & \\
\hline & Total $^{c}(n=2141)$ & No $(n=1335)$ & Yes $(n=806)$ & & & & \\
\hline HIV positive & 148 & 42 & 116 & $1.67(1.05-2.65)$ & 0.029 & $1.79(1.11-2.90)$ & 0.017 \\
\hline Median age, years & $25(22-30)$ & $25(21-30)$ & $25(22-29)$ & $0.99(0.98-1.02)$ & 0.905 & $0.99(0.98-101)$ & 0.365 \\
\hline \multicolumn{8}{|l|}{ Maternal education } \\
\hline$\leq$ Primary & $1167(60)$ & $499(67)$ & $667(45)$ & ref & & ref & \\
\hline Secondary & $678(29)$ & $213(25)$ & $465(37)$ & $1.77(1.42-2.22)$ & $<0.001$ & $1.77(1.42-2.22)$ & $<0.001$ \\
\hline$>$ Secondary & $296(11)$ & $62(8)$ & $234(18)$ & $2.91(2.10-4.04)$ & $<0.001$ & $2.97(2.14-4.11)$ & $<0.001$ \\
\hline \multicolumn{8}{|l|}{ Employed } \\
\hline No & $1312(64)$ & $490(67)$ & $820(44)$ & ref & & ref & \\
\hline Yes & $809(36)$ & $275(33)$ & $53356)$ & $1.23(0.92-1.64)$ & 0.162 & $1.09(0.80-1.50)$ & 0.569 \\
\hline \multicolumn{8}{|c|}{ Has other male partners } \\
\hline No & $2052(97)$ & $740(97)$ & $1312(97)$ & ref & & ref & \\
\hline Yes & $78(3)$ & $30(3)$ & $48(3)$ & $0.94(0.55-1.61)$ & 0.816 & $0.91(0.53-1.58)$ & 0.750 \\
\hline \multicolumn{8}{|c|}{ Intimate partner violence } \\
\hline No & $1247(57)$ & $450(56)$ & 797 (59) & ref & & ref & \\
\hline Yes & $894(43)$ & $324(44)$ & $569(41)$ & $0.89(0.70-1.13)$ & 0.327 & $0.97(0.77-1.23)$ & 0.830 \\
\hline
\end{tabular}

${ }^{a}$ All estimates account for sampling design and clinic-level clustering

${ }^{\mathrm{b}}$ Multivariable model adjusting for maternal age and maternal education

${ }^{c}$ Married women without partner attendance data were excluded from the analysis

attended $\mathrm{MCH}$ were more likely to attend $\geq 4$ ANC visits during pregnancy than women with partners that did not attend $\mathrm{MCH}$ [AOR $=1.67$ (1.36-2.05), $p<0.001]$. Facility delivery was 2 times higher among women whose partners attended ANC $[\mathrm{AOR}=2.00(1.51-2.64)$, $\mathrm{p}<0.001]$, and the prevalence of exclusive breastfeeding at 6 weeks postpartum was higher among women whose partners attended ANC $[$ AOR $=1.70(1.00-2.91)$, $p=0.051]$. There was a 3 times higher likelihood of Bacille Calmette Guerin (BCG) immunization among infants whose fathers attended ANC compared to infants whose fathers did not attend ANC $[\mathrm{AOR}=3.59$ (1.00-12.88), $\mathrm{p}=0.050$ ] (Table 4).

Among 158 HIV-infected women who had partner ANC attendance data, male ANC attendance was associated with a significantly higher prevalence of ARV use for PMTCT; both self-reported $[\mathrm{AOR}=6.16 \quad(1.26-$ 30.41), $\mathrm{p}=0.026$ ] and as verified in the $\mathrm{MCH}$ booklet [AOR $=5.50(0.99-30.40), \mathrm{p}=0.051]$ (Table 4).

\section{Discussion}

In this geographically dispersed facility-based survey in Kenya, we found a relatively high prevalence of partner ANC attendance with more than one-third of male partners attending at least one ANC visit. Male ANC attendance was associated with a higher prevalence of maternal ANC attendance, facility delivery, exclusive breastfeeding, infant BCG immunization, and uptake of
ARVs. To our knowledge this is the first study to provide national estimates of male ANC attendance in Africa. The estimated national prevalence of male ANC attendance in this survey was 33\% overall and 35\% among married women, respectively. In smaller regional studies from Eastern Uganda and Northern Ethiopia, male partner ANC attendance ranged from 5 to $20 \%[22,23]$. While male ANC attendance in this survey is higher than in previous studies, there remains considerable room for improvement [15, 20, 24].

Men's attitudes, perceptions, and understanding of $\mathrm{MCH}$ services influences their support of maternal access to these services [7]. Thus, male education is a gateway to increasing male support of maternal engagement with $\mathrm{MCH}$ services [13, 25-28]. A recent systematic review demonstrated that men's motivation to ensure a safe delivery is an important outcome of male ANC attendance [29]. Approaches to encourage male ANC attendance include use of participatory exercises with men to discuss a father's supportive role [30]. A hospital-based study in Malawi reported a 2-year increase in male partner ANC attendance from less than $1 \%$ to $10.7 \%$ following implementation of peer education, peer-led male-involvement drama, and male-friendly hospital infrastructure [31]. Provision of more convenient clinic attendance options, abbreviated male check-up, calling or visiting men who cannot make it to ANC clinic and HIV testing are opportunities for initiating conversations around maternal health [13-15, 32, 33]. 
Table 4 Male ANC attendance and maternal-infant health outcomes among married women ${ }^{\text {a }}$

\begin{tabular}{|c|c|c|c|c|c|c|c|}
\hline \multirow{3}{*}{ Married women } & \multirow[b]{3}{*}{$\begin{array}{l}\text { Total } \mathrm{n}^{\mathrm{f}} \\
(\mathrm{n}=2141)\end{array}$} & \multirow{2}{*}{\multicolumn{2}{|c|}{$\begin{array}{l}\text { Unweighted N (Weighted \%) or Weighted } \\
\text { Median (IQR) } \\
\text { Partner attended ANC }\end{array}$}} & \multirow[b]{3}{*}{ OR $(95 \% \mathrm{Cl})$} & \multirow[b]{3}{*}{$p$-value } & \multirow[b]{3}{*}{$\begin{array}{l}\text { AOR } \\
(95 \% \mathrm{Cl})^{\mathrm{b}}\end{array}$} & \multirow[b]{3}{*}{$p$-value } \\
\hline & & & & & & & \\
\hline & & $\begin{array}{l}\text { No } \\
(n=1335)\end{array}$ & $\begin{array}{l}\text { Yes } \\
(n=806)\end{array}$ & & & & \\
\hline ANC visits & 2141 & & & & & & \\
\hline$\geq 4$ ANC visits & & $556(40)$ & $468(57)$ & $1.98(1.59-2.48)$ & $<0.001$ & $1.67(1.36-2.05)$ & $<0.001$ \\
\hline$<4$ ANC visits & & $731(60)$ & $306(43)$ & & & & \\
\hline Not recorded & & 48 & 32 & & & & \\
\hline Skilled delivery & 2141 & & & & & & \\
\hline Yes & & $976(68)$ & $700(85)$ & $2 \cdot 62(1.97-3.50)$ & $<0.001$ & $2.00(1.51-2.64)$ & $<0.001$ \\
\hline No & & $359(32)$ & $106(15)$ & & & & \\
\hline Not recorded & & 0 & 0 & & & & \\
\hline $\begin{array}{l}\text { 6-week Exclusive breastfeeding among women } \\
\text { attending week } 6 \text { visitc }^{\complement}\end{array}$ & 1278 & & & & & & \\
\hline Yes & & $718(90)$ & $453(95)$ & $1.98(1.07-3.69)$ & 0.031 & $1.70(1.00-2.91)$ & 0.051 \\
\hline No & & $76(10)$ & $31(5)$ & & & & \\
\hline Not recorded & & 0 & 0 & & & & \\
\hline $\begin{array}{l}\text { 6-month Exclusive breastfeeding among women } \\
\text { attending month } 9 \text { visit }{ }^{d}\end{array}$ & 863 & & & & & & \\
\hline Yes & & $390(70)$ & $242(74)$ & $1.18(0.80-1.75)$ & 0.397 & $1.08(0.75-1.54)$ & 0.680 \\
\hline No & & $151(30)$ & $80(26)$ & & & & \\
\hline Not recorded & & 0 & 0 & & & & \\
\hline HIV+ married women & $n=158$ & & & & & & \\
\hline ARVs for PMTCT (self-report) & 158 & & & & & & \\
\hline Yes & & $49(72)$ & $33(95)$ & $7.05(1.51-32.84)$ & 0.013 & $6 \cdot 16(1 \cdot 26-30 \cdot 41)$ & 0.026 \\
\hline No & & $11(28)$ & $3(5)$ & & & & \\
\hline Not recorded & & 46 & 16 & & & & \\
\hline ARVs for PMTCT (verified in MCH book) & 158 & & & & & & \\
\hline Yes & & $33(61)$ & $19(92)$ & $7.02(1.41-34.89)$ & 0.018 & $5.50(0.99-30.40)$ & 0.051 \\
\hline No & & $11(39)$ & $3(8)$ & & & & \\
\hline Not recorded & & 62 & 30 & & & & \\
\hline All Infants & Total $n$ & $n=1335$ & $n=806$ & OR $(95 \% \mathrm{Cl})$ & p-value & $\operatorname{AOR}(95 \% \mathrm{Cl})^{\mathrm{a}}$ & $p$-value \\
\hline Infant $\mathrm{BCG}^{\mathrm{e}}$ immunization & 2141 & & & & & & \\
\hline Yes & & $1317(98)$ & $803(100)$ & $4.45(1.23-16.09)$ & 0.023 & $3.59(1.00-12.88)$ & 0.050 \\
\hline No & & $18(2)$ & $3(0)$ & & & & \\
\hline Not recorded & & 0 & 0 & & & & \\
\hline HIV-exposed infants & Total $n$ & & & & & & \\
\hline Infant received ARVs for PMTCT & 158 & & & & & & \\
\hline Yes & & 99 (98) & $48(95)$ & $0.34(0.05-2.33)$ & 0.270 & $0.30(0.04-2.18)$ & 0.225 \\
\hline No & & $4(2)$ & $3(5)$ & & & & \\
\hline Not recorded & & 3 & 1 & & & & \\
\hline Infant had a HIV PCR test & 158 & & & & & & \\
\hline Yes & & $51(43)$ & $26(53)$ & $1.53(0.69-3.39)$ & 0.292 & $1.59(0.73-3.47)$ & 0.241 \\
\hline No & & $29(57)$ & $16(47)$ & & & & \\
\hline Not recorded & & 26 & 10 & & & & \\
\hline
\end{tabular}

${ }^{\mathrm{a} A l l}$ estimates account for sampling design and clinic-level clustering

${ }^{\mathrm{b}}$ Multivariable model adjusting for maternal age and maternal education

'Measured among women attending week-6 postpartum visit, and adjusted for maternal HIV status

${ }^{\mathrm{d}}$ Measured among women attending month-9 postpartum visit

'Bacille Calmette Guerin

${ }^{f}$ Married women without partner attendance data were excluded from the analysis 
We found that a woman having a male partner who was younger and more educated and having fewer children increased the male partner's likelihood of attending ANC. Among married women, being younger, higher education, absence of partner violence, and higher socioeconomic status were associated with male ANC attendance. Male partners in longer duration relationships were significantly less likely to attend ANC. Similarly, previous studies have shown that marital status, employment, awareness of ANC benefits, male perceptions, living with female partner, distance from facility, and intimate partner violence significantly affect male ANC attendance $[9,20,30,34]$.

Analysis of self-reported information revealed that mothers' simply requesting their partners to attend ANC increased their partners' likelihood of attending ANC 13-fold. Additionally, higher maternal education was associated with higher chances of requesting partners to attend ANC. While male perceptions are important determinants of ANC attendance, women's perceptions and initiative to request partners to accompany them to ANC are significantly influential. This is a significant finding as $\mathrm{MCH}$ programs could increase male partner involvement by equipping women with the skills and tools necessary to invite or request their male partners to attend ANC [35]. Partner invitation to clinic could potentially be important for those men in longer duration relationships who may be less likely to attend clinic. This is consistent with findings from studies in Tanzania, South Africa, and Ethiopia in which invitation of partners catalyzed their ANC attendance [12, 22, 35].

In Kenya, widespread campaigns have been used to encourage male partner engagement in $\mathrm{MCH}$ activities $[10,17,30,32]$. Regional efforts are primarily driven by non-governmental organizations (NGOs) $[18,30,32$, 36]. Population Services International (PSI) conducted campaigns aimed at increasing male involvement in PMTCT and reported an increase in partner support following campaigns [36]. The "Tunza" family health network by PSI promoted male involvement and support for maternal contraception use [36]. ICAP at Columbia University, Kenya's "Egemesha Wanawake Program" was an intervention targeting male partners' knowledge and skills to support family access to $\mathrm{MCH}$ services [30]. The Family AIDS Care and Education Services (FACES) initiative aimed at increasing male ANC attendance, reported increase from $7.4 \%$ to $54.2 \%$ male attendance among 7236 women [32]. We posit that the relatively high prevalence of male partner attendance that we observed may reflect these efforts and demonstrates significant progress in Kenya [14, 15]. In Rwanda, men have been encouraged to become involved in pregnancy and PMTCT care following a government initiative [37]. In Kenya, more remains to be done with regard to creating national policies that support partner ANC attendance efforts.

In our study, male ANC attendance was associated with uptake of multiple health services including maternal adherence to 4 or more ANC visits, facility delivery, and infant BCG immunization. Globally, access to facility delivery alone can reduce maternal mortality by $16-33 \%$ [38]. We also found that women whose male partners attended clinic and were engaged in their care were more likely to exclusively breastfeed. The health of a child depends on that of the mother, and delivery of effective $\mathrm{MCH}$ interventions to women could avert up to $40 \%$ of deaths in children under five [39]. HIV-infected women were also more likely to use ARVs for PMTCT if their partners attended ANC. In prior studies from Kenya and South Africa, couple-based PMTCT interventions increased uptake of PMTCT $[14,15,17,36$, $40,41]$. We did not detect differences in partner attendance between HIV-infected and HIV-uninfected women, suggesting that married HIV-infected women may access partner support as readily as married HIV-uninfected women.

While male ANC attendance appears to confer many benefits, some women cannot access this support in the absence of a stable partnerships or when in abusive relationships [30]. In our survey, $41 \%$ of women were in abusive partnerships. These women may need tailored interventions to motivate their uptake of services. In addition, male ANC attendance could sometimes lead to negative outcomes [42]. HIV disclosure to partners may result in post-test domestic violence or abandonment $[30,42]$. Due to the cross-sectional nature of our survey, we cannot determine the causal direction between IPV and male attendance. In other studies, IPV has been associated with low uptake of facility delivery and a higher likelihood of morbidity in pregnancy [36, 43, 44]. Our findings suggest that IPV, which is a potential barrier to male support and maternal access to services, should be anticipated and addressed in health programs. Where possible, couples should be linked to domestic violence programs, counselling interventions, and support groups to improve the way couples handle disclosure of important information [30, 42].

A primary strength of our study is the large geographically dispersed sample of $\mathrm{MCH}$ clinics throughout Kenya. Multivariate analysis allowed us to adjust for potential confounders such as age and education, though there could be residual confounding. We used in-person interviews and validated self-report with maternal and infant records. Mother-infant pairs were selected based on attendance at week- 6 and month-9 infant immunizations, both of which are highly attended. Our study has limitations given that data could have been influenced by social desirability bias as we depended on maternal 
verbal reports. Another limitation is the selection bias with regards to examining infant BCG immunization in that participants were selected from women bringing their infants for routine week 6 or month 9 infant immunizations. Populations coming for immunization are different from those that don't. This could potentially reduce the power to detect a difference between women whose partners attended ANC and those whose partners did not. While we found that male partner ANC attendance was associated with increased likelihood of BCG immunization uptake and ARV use for PMTCT, the confidence intervals are wide indicating that estimates should be interpreted with caution. However, the results are consistent with other published literature that report a positive association between male partner involvement and maternal and child health outcomes.

\section{Conclusion}

Our study demonstrates associations between male partner ANC attendance and maternal ANC visits, facility delivery, exclusive breastfeeding, infant BCG immunization, and maternal ARV use. Male partner ANC attendance may be useful to accelerate progress to achieving better maternal and infant health outcomes. It is possible to increase male partner ANC attendance regardless of HIV status. This strategy should to be pursued given the benefits conferred to maternal child health. Concerted programmatic efforts are needed to support mothers in inviting their partners to ANC, with special considerations for women who experience intimate partner violence and those of low socioeconomic status for whom engaging male partners may be especially challenging.

\section{Abbreviations \\ ANC: Antenatal Care; ART: Antiretroviral Therapy; ARVs: Antiretroviral drugs; BCG: Bacille Calmette Guerin; CDC: U.S. Centers for Disease Control and Prevention; Cl: Confidence Intervals; FACES: Family AIDS Care and Education Services; FANC: Focused Antenatal Care; HiTS: Hurt, Insulted, Threatened with harm, and Screamed Domestic Violence screening tool; HIV: Human Immunodeficiency Virus; IPV: Intimate Partner Violence; KEMRI: Kenya Medical Research Institute; MCH: Maternal and Child Health; NASCOP: National AIDS and STI Control Program; NGO: Non-Governmental Organization; OR: Odds Ratio; PCR: Polymerase Chain Reaction; PMTCT: Prevention of Mother-to-Child Transmission of HIV; PNC: Postnatal Care; PSI: Population Services International; WHO: World Health Organization}

\section{Acknowledgements}

We would like to acknowledge and thank all study participants, study staff, the Ministry of Health in Kenya, Centers for Disease Control and Prevention (CDC) -Kenya, and Kenya Medical Research Institute (KEMRI). This work and publication have been supported by the President's Emergency Plan for AIDS Relief (PEPFAR) through the CDC under the terms of the cooperative agreement COAG\#U2GPS002047.

\section{Authors' contributions}

CJM, GJS, AL, AK and LN designed the study and participated in data analysis. BO performed the analysis with guidance from all the authors. CJM and $\mathrm{AL}$ contributed to data collection. The primary author, $\mathrm{BO}$, is responsible for the completeness and accuracy of the data presented, as well as adherence of this report to the study protocol. All authors, CJM, GJS, JP, AL,
$A K, J K, B S$, and $L N$ contributed to the writing of this paper. All authors contributed to review of the manuscript and approved the final draft.

\section{Funding}

The study was funded by the President's Emergency Plan for AIDS Relief (PEPFAR) and Centers for Disease Control and Prevention

(COAG\#U2GPS002047). The funders participated in design of the study, collection and interpretation of the data, and in review of this manuscript.

\section{Availability of data and materials}

The datasets used and/or analyzed during the current study are available from the corresponding author on reasonable request.

\section{Ethics approval and consent to participate}

Ethical approvals were obtained from the University of Washington Human Subjects Division, the Kenya Medical Research Institute Ethical Review Committee, and the Associate Director for Science at the U.S. Centers for Disease Control and Prevention. All participants provided written informed consent prior to enrollment in the study.

Consent for publication

Not applicable.

\section{Competing interests}

The authors declare that they have no competing interests.

\section{Author details}

${ }^{1}$ Department of Global Health, University of Washington, 325 9th Ave \#359909, Seattle, WA, USA. ²Department of Nursing, University of Washington, Health Sciences Building, T-301, 1959 NE Pacific St, Seattle, WA, USA. ${ }^{3}$ Department of Medicine, University of Washington, Health Sciences Building, RR-512, 1959 NE Pacific St, Seattle, WA, USA. ${ }^{4}$ Department of Epidemiology, University of Washington, Health Sciences Building, F-262, 1959 NE Pacific St, Seattle, WA, USA. ${ }^{5}$ United States Centers for Disease Control and Prevention (CDC), P.O. Box 606-00621, Village Market, Nairobi, Kenya. ${ }^{6}$ Center for Microbiology Research and Center for Clinical Research, Kenya Medical Research Institute, P.O. Box 19464-00202, Nairobi, Kenya. ${ }^{7}$ Department of Research \& Programs, Kenyatta National Hospital, P.O. Box 20723-00202, Nairobi, Kenya.

Received: 5 April 2019 Accepted: 29 July 2019

Published online: 08 August 2019

\section{References}

1. Trends in Maternal Mortality: 1990-2013. Estimates by WHO, UNICEF, UNFPA The World Bank and the United Nations Population Division. Executive Summary. 2014. Accessed March 23, 2019 [https://www.who.int/ reproductivehealth/publications/monitoring/maternal-mortality-2013/en/]

2. Kenya National Bureau of Statistics (KNBS) and ICF Macro. Kenya Demographic and Health Survey 2008-09. Calverton: KNBS and ICF Macro; 2010.

3. Maternal Mortality. Fact sheet. Accessed March 23, 2019 [http://www.who. int/mediacentre/factsheets/fs348/en/]

4. Pell C, Menaca A, Were F, Afrah NA, Chatio S, Manda-Taylor L, Hamel MJ, Hodgson A, Tagbor H, Kalilani L, et al. Factors affecting antenatal care attendance: results from qualitative studies in Ghana, Kenya and Malawi. PLoS One. 2013;8(1):e53747.

5. Family Planning in Kenya: Not for Women Only. Accessed March 23, 2019 [http://www.unfpa.org/public/News/pid/3015]

6. Promoting gender equality: Engaging men and boys. Assessed March 23, 2019 [http://www.unfpa.org/gender/men.htm]

7. USAID. Men Key to Reducing Maternal Deaths in Developing Countries. Frontlines. 2010. http://www.mchip.net/node/119

8. Odeny BM, Pfeiffer J, Farquhar C, Igonya EK, Gatuguta A, Kagwaini F, Nduati R, Kiarie J, Bosire R. The Stigma of Exclusive Breastfeeding Among Both HIVPositive and HIV-Negative Women in Nairobi, Kenya. Breastfeed Med. 2016; 11:252-8.

9. Mangeni J, Mwangi A, Mbugua S, Mukthar V. Male involvement in maternal health care as a determinant of utilization of skilled birth attendants in Kenya. USAID. In: DHS working papers. vol. 93. Calverton: ICF International: 2013. p. 31. 
10. Dunlap J, Foderingham N, Bussell S, Wester CW, Audet CM, Aliyu MH. Male involvement for the prevention of mother-to-child HIV transmission: a brief review of initiatives in east, west, and Central Africa. Curr HIV/AIDS Rep. 2014;11(2):109-18.

11. Ediau M, Wanyenze RK, Machingaidze S, Otim G, Olwedo A, Iriso R, Tumwesigye NM. Trends in antenatal care attendance and health facility delivery following community and health facility systems strengthening interventions in northern Uganda. BMC Pregnancy Childbirth. 2013:13:189.

12. Mohlala BK, Gregson S, Boily MC. Barriers to involvement of men in ANC and VCT in Khayelitsha, South Africa. AIDS Care. 2012;24(8):972-7.

13. Grady WR, Tanfer K, Billy JO, Lincoln-Hanson J. Men's perceptions of their roles and responsibilities regarding sex, contraception and childrearing. Fam Plan Perspect. 1996;28(5):221-6.

14. Aluisio A, Richardson BA, Bosire R, John-Stewart G, Mbori-Ngacha D, Farquhar C. Male antenatal attendance and HIV testing are associated with decreased infant HIV infection and increased HIV-free survival. J Acquir Immune Defic Syndr. 2011;56(1):76-82.

15. Farquhar C, Kiarie JN, Richardson BA, Kabura MN, John FN, Nduati RW, Mbori-Ngacha DA, John-Stewart GC. Antenatal couple counseling increases uptake of interventions to prevent HIV-1 transmission. J Acquir Immune Defic Syndr. 2004;37(5):1620-6.

16. Mageni JN, Mwagni A, Mbugua S, Mukthar V. Male involvement in maternal health care as a determinant of utilization of skilled birth attendants in Kenya. In: DHS working papers no 93. Calverton: ICF International; 2013.

17. Role of male partners in the prevention of mother-to-child HIV transmission Accessed March 23, 2019 [http://www.dovepress.com/role-of-male-partnersin-the-prevention-of-mother-to-child-hiv-transmi-peer-reviewed-article-RRN]

18. Wettstein C, Mugglin C, Egger M, Blaser N, Vizcaya LS, Estill J, Bender N, Davies MA, Wandeler G, Keiser O. Missed opportunities to prevent motherto-child-transmission: systematic review and meta-analysis. AIDS. 2012; 26(18):2361-73.

19. Brusamento S, Ghanotakis E, Tudor Car L, van-Velthoven MH, Majeed A, Car J. Male involvement for increasing the effectiveness of prevention of mother-to-child HIV transmission (PMTCT) programmes. Cochrane Database Syst Rev. 2012;10:CD009468.

20. Katz DA, Kiarie JN, John-Stewart GC, Richardson BA, John FN, Farquhar C. Male perspectives on incorporating men into antenatal HIV counseling and testing. PLoS One. 2009;4(11):e7602.

21. "HITS" A domestic violence screening tool for use in the community. 2003. Accessed May 23, 2018 [http://www.omniaeducation.com/whav/WHAV_ Addenda/Domestic_Violence_Screening_Tools.pdf]

22. Haile F, Brhan Y. Male partner involvements in PMTCT: a cross sectional study, Mekelle, northern Ethiopia. BMC Pregnancy Childbirth. 2014;14:65

23. Byamugisha R, Tumwine JK, Semiyaga N, Tylleskar T. Determinants of male involvement in the prevention of mother-to-child transmission of HIV programme in eastern Uganda: a cross-sectional survey. Reprod Health. 2010;7:12.

24. Nungari M, Njuguna S. Factors influencing male participation in antenatal care in Kenya: A case of Kenyatta National Hospital, Nairobi, Kenya. Mast. Nairobi: University of Nairobi; 2014.

25. Drennan M: Reproductive health: new perspectives on men's participation Population Reports. Series J, No 46 Baltimore, Johns Hopkins School of Public Health, Population Information Program. 1998.

26. August F, Pembe AB, Mpembeni $R$, Axemo P, Darj E: Community health workers can improve male involvement in maternal health. In.

27. Mersha AG. Male involvement in the maternal health care system: implication towards decreasing the high burden of maternal mortality. BMC Pregnancy Childbirth. 2018;18(1):493. https://doi.org/10.1186/s12884-018-213 9-9.

28. Zamawe CF, Masache GC, Dube AN. The role of the parents' perception of the postpartum period and knowledge of maternal mortality in uptake of postnatal care: a qualitative exploration in Malawi. Int J Womens Health. 2015;7:587-94. https://doi.org/10.2147/IJWH.S83228. eCollection 2015.

29. Aguiar $C$, Jennings L. Impact of male partner antenatal accompaniment on perinatal health outcomes in developing countries: a systematic literature review. Matern Child Health J. 2015;19(9):2012-9. https://doi.org/10.1007/s1 0995-015-1713-2.

30. Kiarie JN, Farquhar C, Richardson BA, Kabura MN, John FN, Nduati RW, JohnStewart GC. Domestic violence and prevention of mother-to-child transmission of HIV-1. AIDS. 2006;20(13):1763-9.

31. Mphonda SM, Rosenberg NE, Kamanga E, Mofolo I, Mwale G, Boa E, Mwale M, Martinson F, Hoffman I, Hosseinipour MC. Assessment of peer-based and structural strategies for increasing male participation in an antenatal setting in Lilongwe, Malawi. Afr J Reprod Health. 2014;18(2):97-104.

32. Akama E, Mburu M, Mutegi E, Nyanaro G, Otieno JP, Ndolo, Ochanda B, Ojwang' L, Lewis-Kulzer J, Abuogi L, Oyaro P, Cohen CR, Bukusi EA, Onono M. Impact of a Rapid Results Initiative Approach on Improving Male Partner Involvement in Prevention of Mother to Child Transmission of HIV in Western Kenya. AIDS Behav. 2018;22(9):2956-65. https://doi.org/10.1007/s1 0461-018-2140-3.

33. Changing women and avoiding men. Stereo-types and reproductive health programs. 2000. IDS Bulletin 31(2):49-59. Accessed March 23, 2019 [http:// onlinelibrary.wiley.com/doi/10.1111/j.1759-5436.2000.mp31002007.x/pdf]

34. Tweheyo R, Konde-Lule J, Tumwesigye NM, Sekandi JN. Male partner attendance of skilled antenatal care in peri-urban Gulu district, northern Uganda. BMC Pregnancy Childbirth. 2010;10:53.

35. Theuring S, Jefferys LF, Nchimbi P, Mbezi P, Sewangi J. Increasing Partner Attendance in Antenatal Care and HIV Testing Services: Comparable Outcomes Using Written versus Verbal Invitations in an Urban Facility-Based Controlled Intervention Trial in Mbeya, Tanzania. PLoS One. 2016;11(4):e0152734.

36. Goo L, Harlow SD. Intimate partner violence affects skilled attendance at most recent delivery among women in Kenya. Matern Child Health J. 2012; 16(5):1131-7.

37. Rwanda Global AIDS Response Progress Report. 2014. Accessed 23, 2019 [http://www.unaids.org/sites/default/files/country/documents/RWA_ narrative_report_2014.pdf]

38. Can skilled attendance at delivery reduce maternal mortality in developing countries? In V. De Brouwere \& W. Van Lerberghe (Eds.), Safe motherhood strategies: A review of the evidence.(pp. 97-129). Antwerp: ITG Press 2001 Accessed March 23, 2019 [http://www.popline.org/node/232577]

39. Reducing maternal deaths: Evidence and action a strategy by DFID. 2004. Accessed March 23, 2019 [https://www.eldis.org/document/A17899]

40. Osoti AO, John-Stewart G, Kiarie J, Richardson B, Kinuthia J, Krakowiak D, Farquhar C. Home visits during pregnancy enhance male partner HIV counselling and testing in Kenya: a randomized clinical trial. AIDS. 2014; 28(1):95-103.

41. Weiss SM, Peltzer K, Villar-Loubet O, Shikwane ME, Cook R, Jones DL. Improving PMTCT uptake in rural South Africa. J Int Assoc Provid AIDS Care. 2014;13(3):269-76.

42. RHINO. 2003. Enhancing quality and use of routine health information at district level. Second international workshop, September-October, Eastern Cape, South Africa. MEASURE Evaluation. 2003.

43. Andersson N, Omer K, Caldwell D, Dambam MM, Maikudi AY, Effiong B, Ikpi E, Udofia E, Khan A, Ansari U, et al. Male responsibility and maternal morbidity: a cross-sectional study in two Nigerian states. BMC Health Serv Res. 2011;11(Suppl 2):S7.

44. Stockl H, Filippi V, Watts C, Mbwambo JK. Induced abortion, pregnancy loss and intimate partner violence in Tanzania: a population based study. BMC Pregnancy Childbirth. 2012;12:12.

\section{Publisher's Note}

Springer Nature remains neutral with regard to jurisdictional claims in published maps and institutional affiliations.

Ready to submit your research? Choose BMC and benefit from:

- fast, convenient online submission

- thorough peer review by experienced researchers in your field

- rapid publication on acceptance

- support for research data, including large and complex data types

- gold Open Access which fosters wider collaboration and increased citations

- maximum visibility for your research: over $100 \mathrm{M}$ website views per year

At BMC, research is always in progress.

Learn more biomedcentral.com/submissions 